\title{
Doctors' wellbeing: self-care during the covid-19 pandemic
}

\author{
During a period of increased stress and uncertainty it is more important than ever for NHS staff to \\ look after themselves, say Michael Farquhar and Shreena Unadkat
}

\section{Shreena Unadkat clinical psychologist, Michael Farquhar consultant in sleep medicine}

Sleep medicine department, Evelina London Children's Hospital, UK

In February 2019, Health Education England published the Pearson report looking at the mental wellbeing of NHS staff. It asked about who cares for the people who care for the nation's health and stated, "We must improve the way in which we look after ourselves and our colleagues, so they are better placed to meet the needs of patients."

That reflects a growing consensus-from the General Medical Council, the Royal Colleges, the BMA, and others-that protecting the wellbeing of NHS staff is essential.

The NHS, already under chronic strain, is about to be put under almost unimaginable additional pressure, as we respond to a global public health challenge of a magnitude not seen for generations.

The paradox is that the more pressured things become, the more important it is to pay attention to the wellbeing of our staff. The covid-19 pandemic will almost certainly be a marathon, not a sprint. To continue to deliver the best possible care for its duration, we must support our workforce from the beginning. Looking after ourselves and our colleagues has never been more important; we must give ourselves permission to change "the patient is always first" narrative to "the patient always—but not always first."

When pressure and demand are high, when staff feel they need to stretch to extreme levels to cope, it can seem impossible to stop and take a break. But they are not superhuman.

Pushed to their limits NHS staff, like everyone, become fatigued and performance drops. If breaks are not taken consistently, we run the risk of staff being broken. The NHS workforce is incredibly resilient; it is, however, in danger of believing that resilience means never showing you are tired or stressed.

We must emphasise that regular rest and breaks are for recharging and must be clearly modelled and supported by senior leaders. Most of us start to feel anxious as soon as our phone's battery charge shows red, and we look for sockets to recharge-but we don't always apply the same principles to ourselves.
If we exhaust ourselves sprinting in the first mile of the marathon, the remaining miles will be harder. Stress is a normal human experience that indicates when something needs to change. A better strategy for long term psychological wellbeing is being able to stop.

Paying attention to signs of physiological hyperarousal is a good starting point, as our bodies often indicate that we need to stop long before we admit that we are struggling. Online, brief "body scan" exercises are freely available and can help staff to pause and build awareness of mind and body.

When stressed, sleep becomes more difficult. The temptation is to see sleep as a luxury, not an essential. Supporting NHS staff to get the best sleep they can while responding to the pandemic is critical, because sleep is essential for physical and mental health. Crucially, when we are sleep deprived, our immune systems function less well, increasing our chances of becoming symptomatic on viral exposure.

We can also look after each other by compassionately witnessing and acknowledging the daily experience of working through a global health crisis. This is an evolving situation, and many people have a sense of "unreality." Having other people match our experience is grounding and helps us to make sense of what is happening, which is important for longer term emotional processing.

Being kind to ourselves, and to those around us, is essential.

Many trusts are mobilising their psychological therapists to help frontline staff manage through this time. Staff should check with local psychology leads and occupational health to see what is available.

When the pandemic is over, and we return to some sense of "normal," we will need an even more vigorous discussion about what safe staffing, safe resources, and a safe model of care really mean in the modern NHS.

Our ability to cope with extraordinary demands, like a viral pandemic, depends on our staff having resources and reserves to draw on. We have been drawing on those reserves for a long time now. 
As Michael West said, on publication of the GMC's Caring for Doctors, Caring for Patients report last year, "We can't simply go on the way we are, loading more responsibility onto doctors already struggling to cope. Where workloads are excessive, patient care suffers."

\section{Commissioned, not peer reviewed.}

Published by the BMJ Publishing Group Limited. For permission to use (where not already granted under a licence) please go to http://group.bmj.com/group/rights-licensing/ permissions 